\title{
ELECTRON BEAM DYNAMICS AT OUTPUT MAGNETRON GUN IN GRADIENT MAGNETIC FIELD
}

\author{
A.S. Mazmanishvili, N.G. Reshetnyak \\ National Science Center “Kharkov Institute of Physics and Technology”, Kharkiv, Ukraine \\ E-mail: nreshetnyak@kipt.kharkov.ua
}

The results of numerical calculations based on the electron beam dynamics generated by a magnetron gun in the transport channel in a gradient magnetic field are presented. The dependence of the final transverse distribution on a target on the amplitude and gradient of the magnetic field was investigated. The possibility of controlling the transverse dimensions of the beam has been studied. It was found that the electron flux undergoes radial compression, the magnitude of which is determined by the form of the gradient magnetic field. The main dependences of the electron beam motion in a given magnetic field are modeled. The possibility of adjusting the beam diameter by varying the magnetic field is shown.

PACS: 29.27.Fh

\section{INTRODUCTION}

The study of electron beams of various configurations and intensities is associated with their use in electron-beam technologies, high-voltage pulsed microwave electronics, accelerator technology, etc. [1 - 4]. The range of problems for which electron beams are used is constantly expanding.

At the NSC KIPT studies are being conducted with electron sources with cold cathodes operating in the secondary emission, placed in crossed electric and magnetic fields. A magnetron gun is used as an electron source. The secondary-emission mechanism of beam generation, due to its weakly destructive effect on the cathode material, preserves the emission properties of the electronic source for a long time (according to estimates up to 100 thousand hours).

The paper presents the results of numerical calculations on the formation of an electron beam by a magnetron gun with a secondary-emission cathode. In order to obtain precision characteristics, we studied the formation of a beam with energy of $55 \mathrm{keV}$ in the radial direction when it is transported in a magnetic field, which is created by a solenoid and a permanent magnet. The dependence of the final distribution on a metal target on the amplitude and gradient of the magnetic field along the axis of the system is investigated.

A software tool was built, the use of which made it possible to simulate the main dependences of the motion of an electron beam in a given solenoid magnetic field $[3,4]$. Based on the electron flow model, the possibility of adjusting the beam diameter by varying the magnetic field is shown. The results of numerical simulation of the motion of a tubular electron flow are presented. Attempts to analytically describe the trajectories of particles in a complex magnetic field cause considerable difficulties, which led to the use of numerical methods to obtain results.

Thus, in this work, we consider the problem of studying the process of radial compression of an electron flux, the value of which is determined by the form of the gradient magnetic field.

\section{EXPERIMENTAL EQUIPMENT}

The equipment block diagram is shown in Fig. 1. To obtain an electron beam, a magnetron gun placed in a vacuum volume is used (2). The magnetron gun was powered by a pulsed generator (3) with an amplitude of the flat part of the pulse $20 \ldots 100 \mathrm{kV}$, a duration of $50 \ldots 10 \mu \mathrm{s}$, and a repetition rate of $3 \ldots 10 \mathrm{~Hz}$. Secondary emission propagation in the gun is started by a voltage pulse with a steep drop, which was created by the generator (12) with a voltage amplitude of up to $15 \mathrm{kV}$.

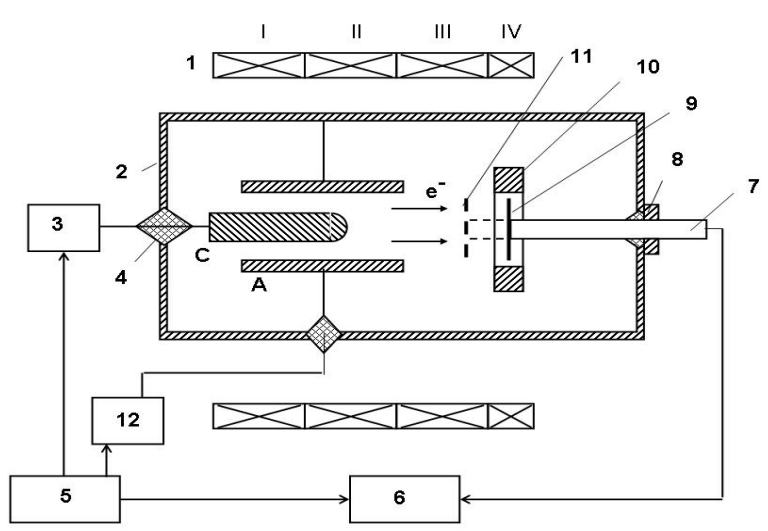

Fig. 1. The block diagram of the experimental setup: 1 - sections of the solenoid (I, II, III, IV); 2 - vacuum volume; 3 - high-voltage pulse generator; 4 -insulator;

5 - synchronization unit; 6 - measuring system;

7 - centering rod; 8 - seal; 9 - Faraday cylinder; 10 - ring magnet; 11 - metal target; 12 - generator; $A$-anode; $C$-cathode

The magnetic field for generating and transporting the beam is created by a solenoid (1), consisting of 4 sections. The amplitude and longitudinal distribution of the magnetic field can be controlled by changing the magnitude of the currents in the coils of the solenoid. An additional magnetic field in the beam transport channel is created by a permanent ring magnet (10) based on a $0.3 \mathrm{~T} \mathrm{NbFeB}$ alloy placed at a distance of $70 \mathrm{~mm}$ from the section of the anode of the magnetron gun. The Faraday cylinder (9) is located in the middle of the permanent magnet and can also be used as a target. The transverse dimensions of the beam are measured by imprinting on metal target sensors $(9,11)$, which were placed at different distances from the anode section. The magnetic field was created jointly by a solenoid and a permanent magnet. 


\section{SIMULATION RESULTS}

A numerical simulation of the compression process of an annular electron beam formed by a magnetron gun was carried out using a given magnetic field formed jointly by a solenoid and a permanent magnet.

In the simulation, we considered a problem in which a stream of electrons with energy $E$ moving parallel to the axis (or at an angle to it) at a certain distance $r_{0}$ from it flies into a given magnetic field. It is required to determine the radial coordinate $r$ at a given distance $z$ for each of the electrons. A generalization is the same problem, but for a beam of initial electrons with a given starting distribution in $r_{0}$ and in directions $r_{0}^{\prime}$. In this case, attention was paid to the influence of the initial distribution of $r_{0}^{\prime}$ on the formation of the radial electron density in the target region.

A program has been built to calculate the trajectory of the motion of electrons in a given magnetic field [3, 4]. From a computational point of view, a problem can be formulated as a Cauchy problem. The stability of the numerical solution algorithm is associated with the step $\Delta s$ of the solution and the Larmor parameter of the problem $\mu$. Thus, if the condition $\mu \Delta s<<1$ is satisfied, we can expect convergence of the numerical solution of the system. By demanding the fulfillment of the given condition (passage of the beam transport channel), it is possible to form the resulting beam and study its properties in the target plane.

The configuration of the magnetic field (see Fig. 2 below) in the system makes it possible to use suitable field models for numerical experiments. In numerical simulation, a field $H(z)$ of the form

$$
H(z)=B(z)+A\left(\frac{1}{2}+\frac{1}{\pi} \operatorname{arctg}\left(\frac{z-z_{L}}{\lambda}\right)\right),
$$

where $B(z)$ is the amplitude of the slowly changing field component, $A$ is the amplitude of the variable component, $z_{L}$ is the coordinate of the middle of the left front of the field, $\lambda$ is the width of the field front. Then the field gradient in the middle of the front is $H^{\prime}\left(z_{L}\right)=A / \lambda$.

In Fig. 2 shows the results of numerical simulation of the motion of an electron beam (sample size $N=500$ particles) in model-type magnetic fields. The dependences of the current particle radii are given depending on the current longitudinal coordinate of the trajectory. From the figures it follows that particles in motion can experience a decrease in their radial size. It can be seen that the direction of movement can be either forward (at $r_{0}^{\prime} \cong 0.0 \mathrm{rad}$ ) or backward (at $\left|r_{0}^{\prime}\right| \geq 10 \mathrm{mrad}$ ). From the above dependences it follows that particles starting at large angles $\left(\left|r_{0}^{\prime}\right| \geq 10 \mathrm{mrad}\right)$ experience a complete reversal of the direction of motion in the magnetic field under consideration.

In Fig. 3 shows the dependences of the same type as in Fig. 2, but for smaller departure angles at the start. It can be seen that in a gradient magnetic field with a short front of the form (1), particles starting at angles of $\left|r_{0}^{\prime}\right| \geq 5 \mathrm{mrad}$ also experience a complete reversal of the direction of motion. Moreover, in all cases, the average radius of motion decreases.

In Figs. 4 and 5 shows the results of numerical simulation of the motion of electrons in the magnetic field under consideration (sample size of the number of particles $N=500$ ).

On the left in Fig. 4 shows the magnetic field configuration in the experimental setup (a part of the field behind the metal target $z \geq 0.245 \mathrm{~m}$ is not indicated), the experimental data are indicated by dots. These data were approximated [3, 4] based on the least squares method. It can be seen that the front of the field is a few millimeters. On the right in Fig. 4 shows the dependence of the average beam size $\langle r\rangle$ on the longitudinal coordinate $z$ of the system obtained as a result of modeling. The initial conditions for the angles at the start were chosen equal to zero.

From Fig. 4 you can see the dynamics of the formation of the distribution of the electron beam during its propagation along the $\mathrm{z}$ axis in the transport channel. Thus, the effect of reducing the transverse dimensions of the electron beam as it moves is well pronounced in the case of a field with a positive gradient.

In Fig. 5 shows the results of numerical simulation of the evolution of particle beam density.

On the left is a set of consecutive beam cross sections during its propagation in a magnetic field (see Fig. 4) along the axis of the system. After starting in an extended section of field decay $(0.13 \mathrm{~m} \leq z \leq 0.18 \mathrm{~m})$, the beam radius increases, and in the region of a magnetic field with a large gradient $(0.18 \mathrm{~m} \leq z \leq 0.21 \mathrm{~m})$ it rapidly decreases, remaining unchanged in the field plateau $(0.21 \mathrm{~m} \leq z \leq 0.23 \mathrm{~m})$.

On the right in Fig. 5 shows two two-dimensional histograms of the cross sections of the beam density at $z=0.135 \mathrm{~m}$ (average beam radius $\langle r\rangle=21 \mathrm{~mm}$ ) and $z=0.205 \mathrm{~m}$ (average beam radius $\langle r\rangle=13 \mathrm{~mm}$ ), characterizing the radial compression of the electron beam.

\section{CONCLUSIONS}

Thus, on the basis of the electron flow model, the characteristics of the resulting electron beam are considered. It follows from the performed modeling calculations that the electron flux undergoes a rearrangement of the radial distribution, which is determined by the amplitude and gradient of the magnetic field in the beam transport channel. A study was made of the dynamics of the motion of electrons for the number of particles equal to 500 in a given magnetic field formed jointly by a solenoid and a permanent magnet. The simulation results on the movement of a tubular electron flow are presented. It is shown that the electron flow experiences radial compression, the magnitude of which is determined by the form of the gradient magnetic field. It was found that by directionally changing the configuration of the magnetic field in order to adjust its gradient, it is possible to control the transverse dimensions of the circular distribution of the electron beam. 

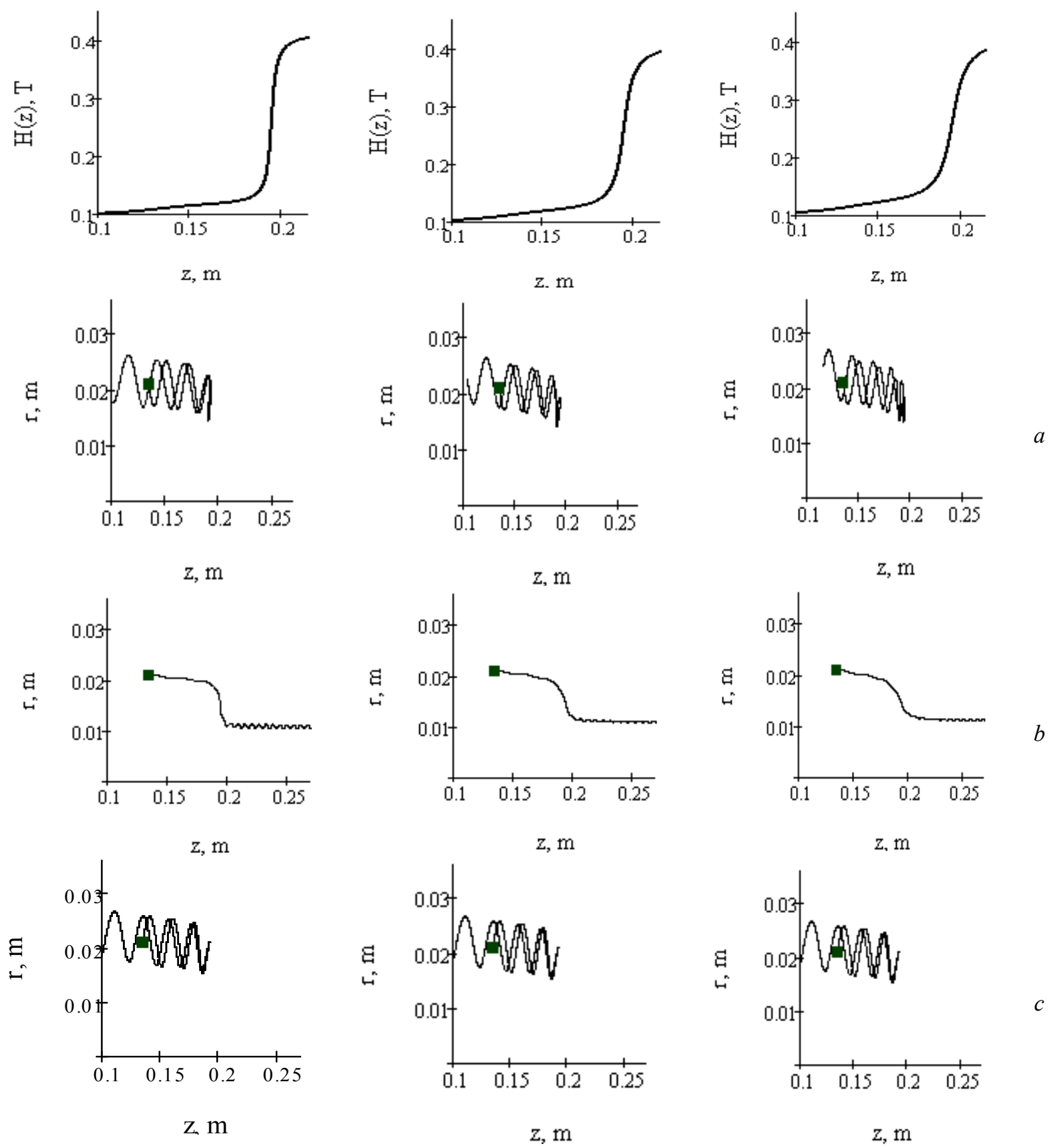

Fig. 2. Modeling particles in a simulating magnetic field (1).

Above is the magnetic field configuration (on the left $\lambda=2 \mathrm{~mm}$, in the middle $\lambda=4 \mathrm{~mm}$, on the right $\lambda=6 \mathrm{~mm}$ ).

Below are sketches of particle trajectories with different directions at the start: $a-r_{0}^{\prime}=-10.0 \mathrm{mrad}$;

$b-r_{0}^{\prime}=0.0 \mathrm{mrad}, c-r_{0}^{\prime}=10 \mathrm{mrad}$. The black square indicates the start point of the electron trajectory 

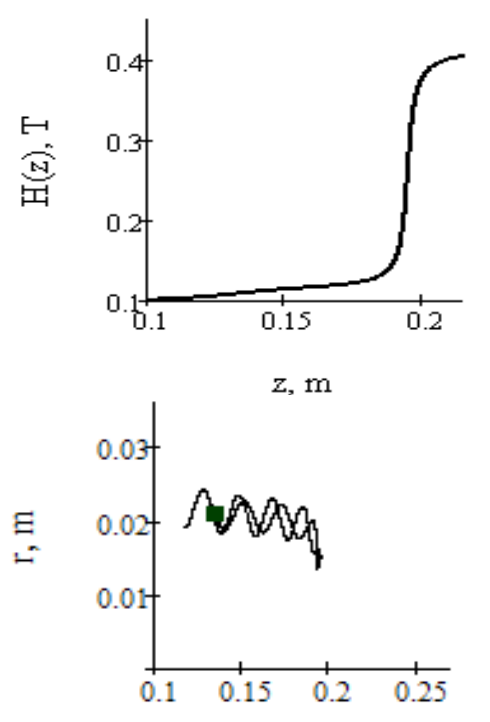

$\mathrm{z}, \mathrm{m}$
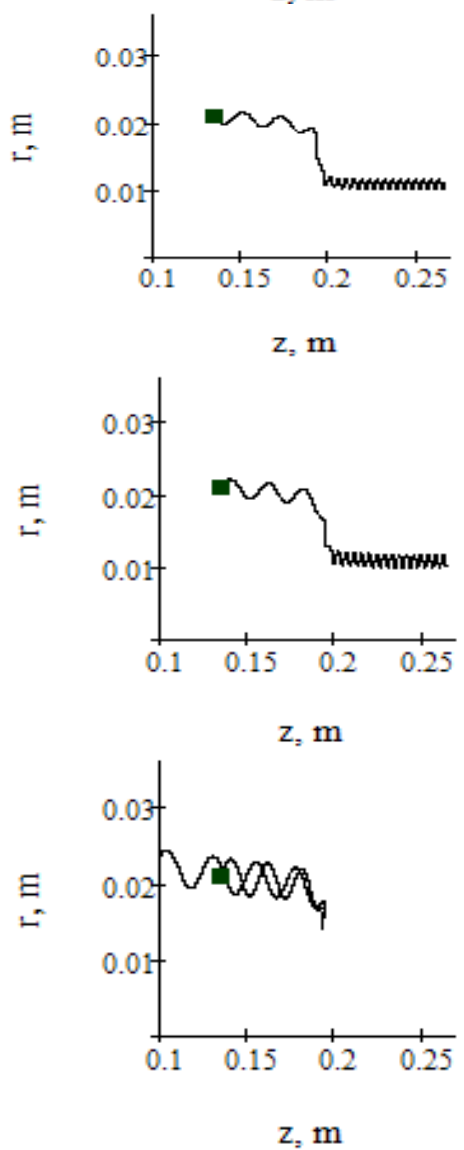

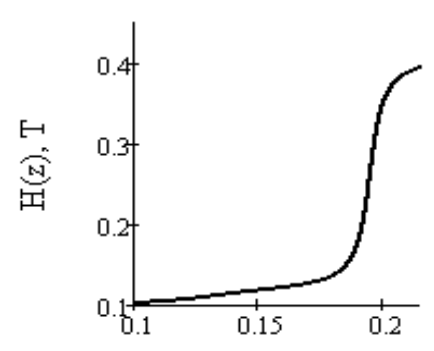

z. $\mathrm{m}$

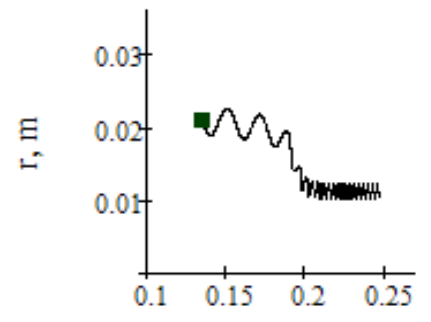

$\mathrm{z}, \mathrm{m}$
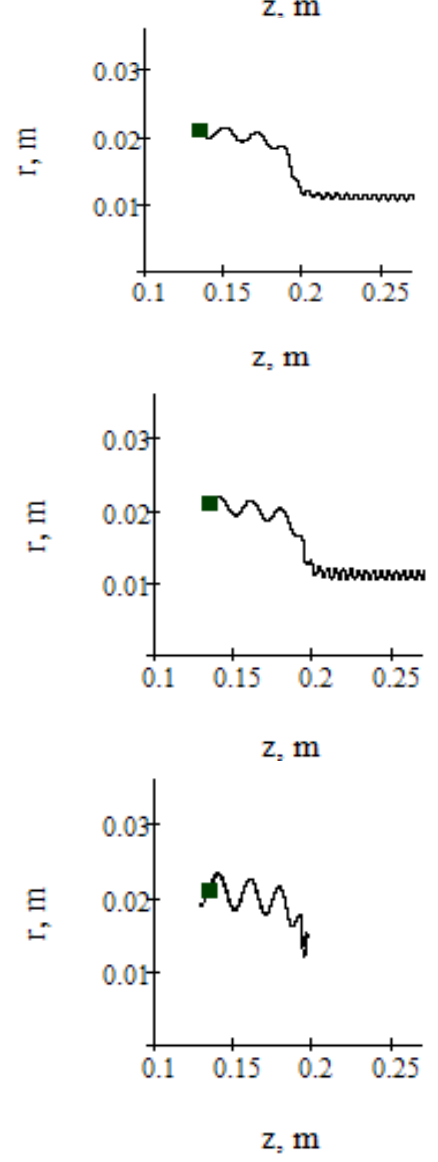

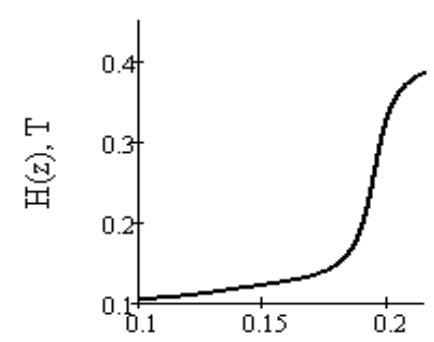

z. $\mathrm{m}$
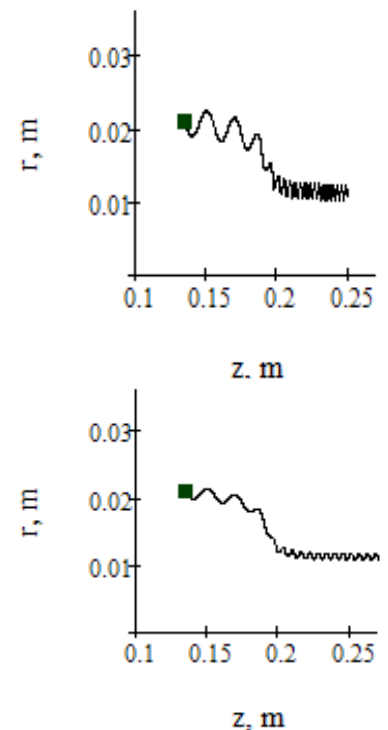

$b$

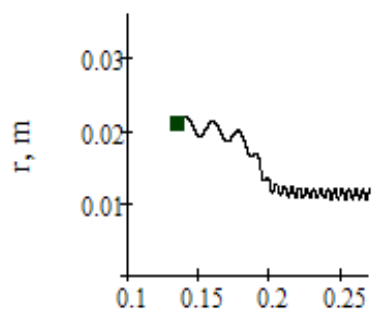

$\mathrm{z}, \mathrm{m}$

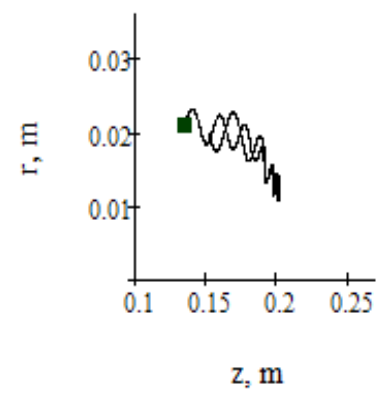

Fig. 3. Trajectories of particles with different directions at the start in a simulating magnetic field (1). The magnetic field configurations are the same as in Fig. 2 (on the left $-\lambda=2 \mathrm{~mm}$, in the middle $-\lambda=4 \mathrm{~mm}$, on the right $-\lambda=6 \mathrm{~mm})$. Vertical dependencies: $a-r_{0}^{\prime}=-5 \mathrm{mrad} ; b-r_{0}^{\prime}=-2.5 \mathrm{mrad} ; c-r_{0}^{\prime}=2.5 \mathrm{mrad}$; $d-r_{0}^{\prime}=5 \mathrm{mrad}$. The black square indicates the start point of the electron trajectory 

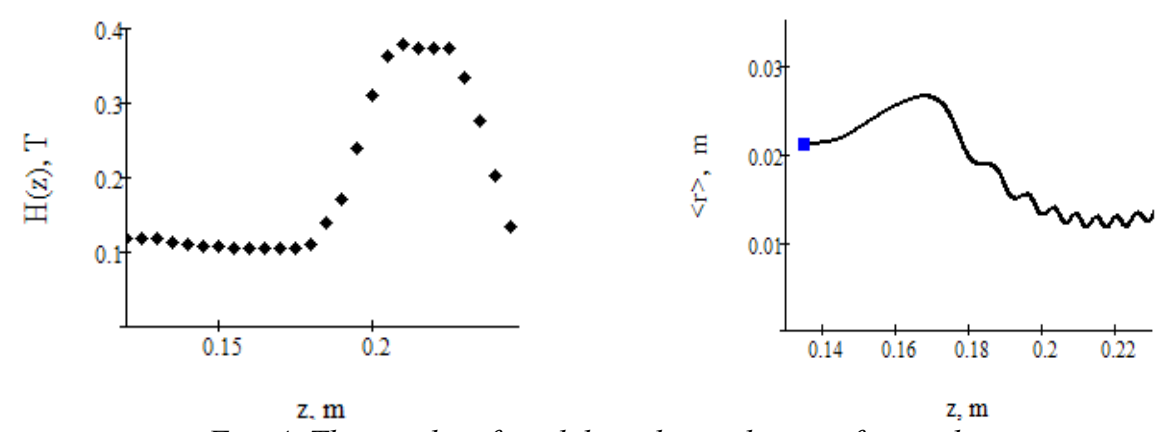

Fig. 4. The results of modeling the evolution of particles.

On the left is the magnetic field configuration in the system. On the right is the dependence of the average radius of the beam $\langle r\rangle$ on the longitudinal coordinate $z$ (the location of the start of motion is indicated by a square)
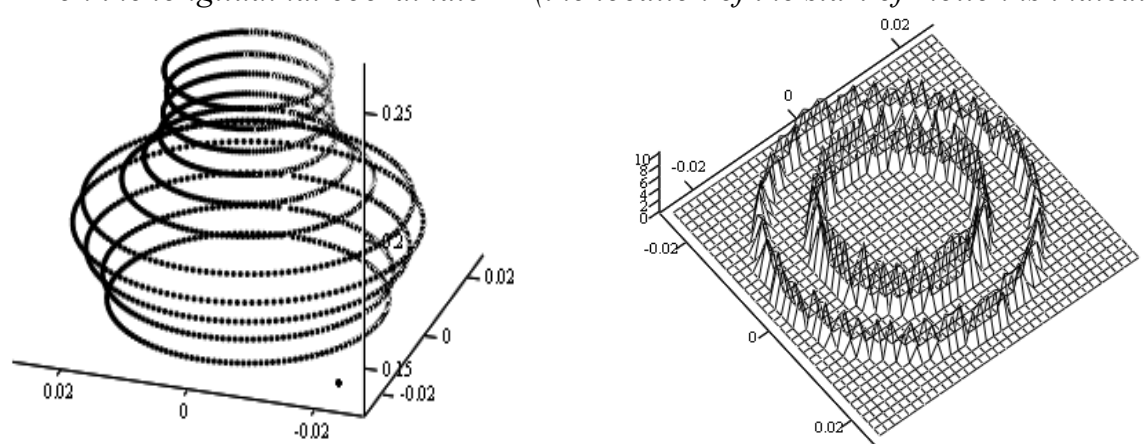

Fig. 5. The results of modeling the evolution of the electron beam, the sample size $N=500$.

On the left is a set of cross sections of the beam profile $(135 \mathrm{~mm} \leq z \leq 205 \mathrm{~mm})$. On the right are two-dimensional histograms of the beam density at the start $(z=135 \mathrm{~mm})$ and on the target plane $(z=205 \mathrm{~mm})$

\section{REFERENCES}

1. V.I. Engelko G. Muller, A. Andreev. Pulse electronbeam equipments (PEBE) for surface treatment // Proc. 10th International Conference on Applied Charged Particle Accelerators in Medicine and Industry. Saint-Petersburg, Russia. 2001, p. 412-417.

2. M.F. Vorogushin, V.A. Glukhikh, G.S. Manukyan, D.A. Karpov, M.P. Svinin, V.I. Engelko, B.P. Yatsenko. Beam and ion-plasma technologies // Problems of Atomic Science and Technology. Series "Physics of Radiation Effects and Radiation Materials Science”. 2002, № 3, p. 101-109.
3. N.I. Aizatsky, A.N. Dovbnya, A.S. Mazmanishvili, N.G. Reshetnyak, V.P. Romasko, I.A. Chertishchev. Research on the formation of a radially directed electron beam generated by a magnetron gun with a secondary emission cathode // Problems of Atomic Science and Technology. Series "Nuclear Physics Investigations”. 2016, № 3, p. 11-16.

4. A.N. Dovbnya, N.A. Dovbnya, A.S. Mazmanishvili, N.G. Reshetnyak, I.A. Chertishchev. Modeling the transfer of a high-current electron beam formed by a magnetron gun with a secondary emission cathode in a decreasing field of a solenoid // Problems of Atomic Science and Technology. Series "Nuclear Physics Investigations”. 2015, № 6, p. 77-82.

Article received 23.09.2019

\section{ДИНАМИКА ЭЛЕКТРОННОГО ПУЧКА НА ВЫХОДЕ МАГНЕТРОННОЙ ПУШКИ В ГРАДИЕНТНОМ МАГНИТНОМ ПОЛЕ}

\section{А.С. Мазманишвили, Н.Г. Решетняк}

Представлены результаты численных расчетов по формированию электронного пучка магнетронной пушкой с вторично-эмиссионным катодом. Изучено формирование пучка в радиальном направлении при движении в магнитном поле соленоида. Исследована зависимость итогового радиального распределения на мишени от амплитуды и градиента магнитного поля вдоль оси системы. Видно, что поток электронов испытывает радиальное сжатие, величина которого определяется видом градиентного магнитного поля. На основе модели движения электронного потока рассмотрены характеристики результирующего электронного пучка.

\section{ДИНАМІКА ЕЛЕКТРОННОГО ПУЧКА НА ВИХОДІ МАГНЕТРОННОЇ ГАРМАТИ В ГРАДІЄНТНОМУ МАГНІТНОМУ ПОЛІ}

\section{О.С. Мазманішвілі, М.Г. Решетняк}

Представлено результати чисельних розрахунків по формуванню електронного пучка магнетронною гарматою з вторинно-емісійним катодом. Вивчено формування пучка в радіальному напрямку його при транспортуванні в магнітному полі соленоїда. Досліджено залежність підсумкового радіального розподілу на мішені від амплітуди і градієнта магнітного поля уздовж осі системи. Видно, що потік електронів відчуває радіальне стиснення, величина якого визначається видом градієнтного магнітного поля. На основі моделі руху електронного потоку розглянуті характеристики результуючого електронного пучка. 